\title{
Weighted voting on the IMF Managing Director
}

\author{
Alexander Mayer ${ }^{1} \cdot$ Stefan $^{\text {Napel }^{1}}{ }^{10}$
}

Received: 4 December 2019 / Accepted: 13 July 2020 / Published online: 27 July 2020

(c) The Author(s) 2020

\begin{abstract}
Executive Directors of the International Monetary Fund elect the Fund's Managing Director from a shortlist of three candidates; financial quotas of IMF members define the respective numbers of votes. The implied a priori distribution of success (preference satisfaction) is compared across different electoral procedures. The USA's Executive Director can expect to come closer to its top preference under plurality rule than for pairwise majority comparisons or plurality with a runoff; opposite applies to everybody else. Differences of US success between voting rules dominate the within-rule differences between most other Directors, and much of the latest reform of quotas.
\end{abstract}

Keywords IMF executive board · IMF quota reform · Weighted voting · Voting procedures $\cdot$ Non-binary voting

\section{Introduction}

The International Monetary Fund (IMF) is one of the key players in today's global financial architecture. Its purpose is to maintain stability and prevent crises in the international monetary system. Most of the IMF's daily business is decided by the Executive Board, which is chaired by the IMF Managing Director (MD). The latter is also the Fund's most visible face to the public and head of its operating staff.

To this day, the MD has always been a European national, pre-selected in informal coordination with the USA; and except for 9 weeks early 2019, when Kristalina Georgieva served as Acting President, the World Bank has similarly been led by an American. Georgieva was named successor to MD Christine Lagarde on 25 September 2019 and started a 5-year term on 1 October 2019. Little detail of her nomination and appointment-which necessitated canceling the maximum age requirement

Stefan Napel

stefan.napel@uni-bayreuth.de

Alexander Mayer

alexander.mayer@uni-bayreuth.de

1 Department of Economics, University of Bayreuth, Bayreuth, Germany 
in the official By-Laws of the IMF-was made public. The Fund has a tradition of aiming for internal agreement without raising external attention.

Emerging market and developing countries have been complaining about intransparent EU and US deals for long and have called for greater say in IMF decisions (see, e.g., Foreign Affairs, 9 June 2011). In January 2016, some of their demands were met. Based on the 14th General Review of Quotas, agreed in 2010, quota changes in favor of emerging economies came into force and it was affirmed that future MDs will be selected from

... a shortlist of three candidates ... without geographical preferences. The shortlisting process will be implemented through indications of which candidates receive the most support among Directors, taking into account the Fund's weighted voting system ... Although the Executive Board may select a Managing Director by a majority of the votes cast, the objective of the Executive Board is to select the Managing Director by consensus ... (IMF Press Release $16 / 19 ;{ }^{1}$ emphasis added).

Practical decision making by the IMF, as by any other organization, may differ from declarations and by-laws. But negotiations and arm-twisting can generally be expected to take place in 'the shadow' of official voting rules: whatever consensus may arise on an issue was likely affected by the ways in which formal votes would have gone. The Fund's weighted voting system has, therefore, received considerable research interest. See, e.g., investigations by Leech (2002, 2003), Alonso-Meijide and Bowles (2005), Aleskerov et al. (2008); Leech and Leech (2013), and Kurz (2016).

Most of these studies have focused on the a priori distribution of voting power in the IMF, operationalized as decisiveness in a binary framework. This note makes similar a priori assumptions - abstracting from historical correlation patterns, alliances, etc. in order to assess the institutional playing field as such-but is novel in two respects.

First, we study success rather than decisiveness. ${ }^{2}$ That is, the (un)levelness of the current distribution of voting rights in the Executive Board is assessed in terms of expected satisfaction of members' preferences rather than the probability to cast a pivotal vote. Second, we consider choice between three candidates shortlisted for the MD position, rather than a binary yes-or-no or $a$ versus $b$ vote. It seems plausible that other decisions by the Executive Board, not just selection of a new MD, and by similar voting bodies can involve more than two options, too. The present study thus complements binary voting analysis more generally.

\footnotetext{
1 Available from www.imf.org/en/News/Articles/2015/09/14/01/49/pr1619.

2 See Barry (1980) and Laruelle and Valenciano (2005) for a conceptual and technical discussion. Success and decisiveness are positive affine transformations of another for independent binary votes. Laruelle et al. (2006, p. 197) stress that "practitioners have often raised objections about the power indices approach ... [and ask] why pay so much attention to decisiveness, when success seems a more important issue for the involved voters?" in the context of weighted voting in the EU. Success presumably is a more important issue also in the IMF's case.
} 


\section{Weighted voting in the IMF}

IMF member countries cast very different numbers of votes depending on their quota, i.e., the country's financial contribution to the Fund, denominated in special drawing rights (SDR). Those who contribute more have more say. Specifically, each member gets one vote for every SDR 100000 plus an equal share of the $5.502 \%$ of total votes that are allocated as "basic votes" to all. The USA have the largest voting weight with about $16.5 \%$ of the total; the smallest member, Tuvalu, has around $0.03 \%$.

The Executive Board comprises 24 Directors. Each of the six financially strongest IMF members (USA, China, Japan, Germany, France, and the UK) and Saudi Arabia currently have an own director. The remaining 182 countries are clustered into seventeen groups with one Director each, representing the joint interest of the group's members. ${ }^{3}$

When a vote is taken, an Executive Director who represents a single country casts as many votes as allotted to his or her country. A Director who represents several countries has a "voting power"- - using the IMF's official term for weight-equal to the combined allotment of all group members. The respective vote shares are indicated in Table 1 below. ${ }^{4}$

\section{Choosing a Managing Director from three candidates}

IMF Press Release 16/19 declared “ ... the Executive Board has adopted an open, merit-based, and transparent process for the selection of the Managing Director ...". If several qualified candidates have been nominated by any IMF Governors or Executive Directors, the Executive Board elects the MD from three shortlisted candidates "by a majority of the votes cast". This assumes there is no consensus or, our preferred interpretation, that whoever is publicly presented as the consensual candidate has actually been the winner of straw votes.

A majority of votes is straightforward to obtain for two, but not for three alternatives. Assume candidates $a, b$, and $c$ are shortlisted. How would vote shares of, e.g., $28.91 \%$ for $a$ (the combined voting powers of the USA, UK, Saudi Arabia, plus the groups represented by Directors from India and Canada), $40.43 \%$ for $b$ (think of Japan, Germany, France as well as the Belgium, Colombia, Italy, Sweden, Australia, and South Africa groups), and the remaining 30.66\% for $c$ be dealt with? That the answer is open (also after an inquiry to the IMF) provides procedural leeway and a case for investigating how details of the adopted election method matter a priori: the

\footnotetext{
3 The groups emerge as part of the election process but their composition has been quite stable over time. Only Uzbekistan, Syria, and Libya switched groups in 2018.

4 We use the group composition as of December 2018. Respective vote shares, including basic votes, have been calculated from the quotas listed in the "14th Review" column of Table 1 from www.imf.org/ external/np/fin/quotas/2018/0818.htm. The current Directors, whose nationalities are shown in Tables 1 and 2, began 2-year terms in November 2018 (except for the one from India, who replaced his deceased predecessor in October 2019).
} 
Table 1 Distance-based success (Directors that represent several members with asterisk)

\begin{tabular}{|c|c|c|c|c|}
\hline & Vote share $(\%)$ & Plurality & Plurality runoff & Copeland \\
\hline USA & 16.47 & 0.8226 & 0.7985 & 0.8108 \\
\hline Japan & 6.13 & 0.5796 & 0.5915 & 0.5903 \\
\hline China & 6.07 & 0.5786 & 0.5905 & 0.5892 \\
\hline Belgium* & 5.41 & 0.5697 & 0.5807 & 0.5795 \\
\hline Germany & 5.31 & 0.5682 & 0.5791 & 0.5779 \\
\hline Colombia* & 5.29 & 0.5680 & 0.5789 & 0.5777 \\
\hline Thailand* & 4.33 & 0.5552 & 0.5647 & 0.5636 \\
\hline Italy* & 4.12 & 0.5524 & 0.5614 & 0.5603 \\
\hline France & 4.02 & 0.5510 & 0.5600 & 0.5589 \\
\hline United Kingdom & 4.02 & 0.5510 & 0.5600 & 0.5589 \\
\hline Australia* & 3.78 & 0.5479 & 0.5564 & 0.5554 \\
\hline Canada* & 3.37 & 0.5424 & 0.5502 & 0.5493 \\
\hline Sweden* & 3.28 & 0.5413 & 0.5490 & 0.5480 \\
\hline Turkey* & 3.22 & 0.5406 & 0.5482 & 0.5473 \\
\hline South Africa* & 3.09 & 0.5388 & 0.5461 & 0.5451 \\
\hline Brazil* & 3.06 & 0.5385 & 0.5457 & 0.5449 \\
\hline India* & 3.04 & 0.5382 & 0.5453 & 0.5445 \\
\hline Switzerland* & 2.88 & 0.5362 & 0.5430 & 0.5422 \\
\hline Russian Federation* & 2.83 & 0.5354 & 0.5422 & 0.5413 \\
\hline Iran* & 2.54 & 0.5317 & 0.5378 & 0.5371 \\
\hline Egypt* & 2.52 & 0.5314 & 0.5375 & 0.5368 \\
\hline Saudi Arabia & 2.01 & 0.5249 & 0.5299 & 0.5293 \\
\hline Mauritania* & 1.62 & 0.5200 & 0.5242 & 0.5236 \\
\hline Argentina* & 1.59 & 0.5196 & 0.5238 & 0.5232 \\
\hline
\end{tabular}

same preference configuration may give rise to different winners, depending on the procedural choice, and the same voting weights induce different expected success for individual voters.

We consider three methods that are compatible with the IMF's reference to "a majority of the votes cast". ${ }^{5}$ First, it is conceivable that "majority" is interpreted in the weak sense of a plurality, sometimes referred to as "relative majority" in British English. Then $b$ would be elected for above ballot. The second method, plurality with a runoff, prescribes a second ballot between only the two front runners of the first (unless one gained $>50 \%$ already). This second round almost surely produces a majority winner and, for above scenario, gives $a$ 's supporters the chance to obtain at least their second preference. The third option is known as Copeland rule: compare all candidates in pairwise majority votes and select the one with most victories. ${ }^{6}$

\footnotetext{
5 The rules become equivalent if only two candidates are shortlisted.

${ }^{6}$ A possible cycle-e.g., $a$ wins a majority against $b$; $b$ wins against $c ; c$ wins against $a$-yields one victory for each candidate. We break any such ties lexicographically.
} 
Table 2 Top choice probabilities

\begin{tabular}{lclll}
\hline & Vote share $(\%)$ & Plurality & Plurality runoff & Copeland \\
\hline USA & 16.47 & 0.7635 & 0.7196 & 0.7109 \\
Japan & 6.13 & 0.4394 & 0.4371 & 0.4296 \\
China & 6.07 & 0.4381 & 0.4358 & 0.4284 \\
Belgium* & 5.41 & 0.4262 & 0.4240 & 0.4174 \\
Germany & 5.31 & 0.4243 & 0.4222 & 0.4158 \\
Colombia* & 5.29 & 0.4241 & 0.4219 & 0.4155 \\
Thailand* & 4.33 & 0.4069 & 0.4052 & 0.3999 \\
Italy* & 4.12 & 0.4032 & 0.4014 & 0.3964 \\
France & 4.02 & 0.4014 & 0.3996 & 0.3948 \\
United Kingdom & 4.02 & 0.4014 & 0.3996 & 0.3948 \\
Australia* & 3.78 & 0.3971 & 0.3956 & 0.3910 \\
Canada* & 3.37 & 0.3899 & 0.3884 & 0.3844 \\
Sweden* & 3.28 & 0.3884 & 0.3870 & 0.3831 \\
Turkey* & 3.22 & 0.3875 & 0.3862 & 0.3823 \\
South Africa* & 3.09 & 0.3850 & 0.3837 & 0.3799 \\
Brazil* & 3.06 & 0.3847 & 0.3834 & 0.3797 \\
India* & 3.04 & 0.3843 & 0.3830 & 0.3794 \\
Switzerland* & 2.88 & 0.3815 & 0.3803 & 0.3768 \\
Russian Federation* & 2.83 & 0.3806 & 0.3794 & 0.3759 \\
Iran* & 2.54 & 0.3755 & 0.3744 & 0.3714 \\
Egypt* & 2.52 & 0.3752 & 0.3742 & 0.3711 \\
Saudi Arabia & 2.01 & 0.3665 & 0.3657 & 0.3633 \\
Mauritania* & 1.62 & 0.3600 & 0.3593 & 0.3573 \\
Argentina* & 1.59 & 0.3594 & 0.3588 & 0.3569 \\
\hline Directors that & & & &
\end{tabular}

Directors that represent several members with asterisk

\section{Quantifying expected success}

We assume that all 24 Directors vote sincerely based on linear preference orderings over three given candidates. We distinguish two notions of (expected) success. ${ }^{7}$ The first is based on the rank distance between the voting outcome and respective Board member's most-preferred candidate: if, e.g., a Director's preference is $a>b>c$ then victory of $a$ brings him or her a success score of 1 , victory of $b$ gives $1 / 2$, and if $c$ wins then the Director's success is 0 . The second notion ascribes positive success to a Director only if the respective most-preferred candidate wins. For $a>b>c$, this amounts to a success score of 1 in case $a$ is elected and 0 otherwise. The expected success of a given Director under this notion equals the probability that his or her top choice is elected.

\footnotetext{
7 They coincide in the binary scenarios considered by Laruelle and Valenciano (2005) and Laruelle et al. (2006).
} 
Expectations will be based on the a priori assumption that all six linear orderings over three candidates appear with equal probability and independently across Directors. This reflects the impartial culture assumption of social choice analysis. The motivation is that, exactly as in corresponding binary voting power analysis, we seek to assess the IMF's weighted voting system from behind a constitutional 'veil of ignorance'. That is, we ignore fluctuating political alliances, correlation patterns, or particular candidate characteristics in order to evaluate the playing field created by voting weights as such, adopting a normative perspective. The implied caveat is that our calculations do not identify (or predict) who is how successful from a positive perspective.

\section{Results}

Exact evaluation of all $6^{24}>4.7 \times 10^{18}$ discrete preference configurations in the Executive Board is computationally infeasible. We have therefore approximated expected values by numerical averages in an extensive Monte Carlo study. The latter used enough iterations (50 mio.) such that any differences involving the first three decimal places in Tables 1 and 2 are significant at the 95\% confidence level. Table 1 reports success based on rank distances; Table 2 the corresponding probabilities for the Director's top choice to win.

It makes a noticeable difference which procedural interpretation of electing a shortlisted candidate "by a majority of the votes cast" is adopted: distance-based success for the USA is highest for a plain plurality vote, second-highest for pairwise majority comparisons, and lowest for plurality voting with a runoff. For all other Directors, it is the opposite: plurality runoff a priori has a small edge over Copeland rule; both yield greater expected success than plurality.

The difference of $\approx 0.024$ in Table 1 between the USA's a priori success under plurality with and without a runoff is bigger than the effect of any \pm 1 percentage point difference in vote shares. It exceeds, for instance, the plurality success difference between the Thai Director, Alisara Mahasandana, who wields the 7th highest vote share with $4.33 \%$ of the total, and her Iranian peer, Jafar Mojarrad, near the table's bottom with $2.54 \%$. Leaving aside China - as the only IMF member that saw its quota increase drastically by +2.26 percentage points-the rule by which the Executive Board selects from three options or candidates is more relevant than any of the quota adjustments for emerging economies in the 14th General Review of Quotas.

Table 2 indicates a slight advantage of plurality rule for all Executive Board members: plurality decisions come with the highest chances to have one's most-preferred candidate elected. But, inferring the probability of a Director's second choice being elected from the difference between entries in Tables 1 and 2, all except the US Director also face greater risk of ending up with their least-preferred candidate. Pairwise comparisons or requiring a runoff when no candidate attracted $>50 \%$ of votes are safer bets.

Every Director's top choice probability in Table 2 strictly exceeds the success benchmark $1 / 3$ of a 'null player' whose voting weight is zero. The extra success 
derived from positive voting weight is, however, nonlinear: it is 16.5 times greater for the largest member USA (with $0.7635-1 / 3 \approx 0.430$ ) than for the Argentina group (0.026), which has the least votes; while the corresponding voting weights differ by a factor of less than 10.5 .

\section{Concluding remarks}

At the 2019 Annual Meetings of the World Bank Group and the IMF in mid-October, the Communiqué of the 40th Meeting of the IMFC pointed out " ... lack of progress on a quota increase under the 15th Review" and called on the Executive Board to complete its work as soon as possible. ${ }^{8}$ The Communiqué envisions adjustments towards higher quota shares for emerging market and developing countries, but such change tends to be slowed down or vetoed. It is hence noteworthy that using procedural leeway on, e.g., the implementation of majority requirements can matter significantly more than long-fought percentage point shifts of relative quotas.

In words of William Riker (1982), “ ... there is no fair way to ensure that there will be exactly two alternatives" (p. 60) and having "... more than two alternatives on any issue ... is almost always the case for any reasonably free, open, and fair political system ..." (p. 234). It is necessary, therefore, to look closely at the stages preceding a yes-or-no vote and pertinent procedures. The IMF's election of a new MD provides a case in point. It involves weighted voting on three alternatives (or yet more before the shortlisting). We would be surprised if other issues that involve (straw) voting by the IMF Executive Board—or the larger IMF Board of Governors, shareholder meetings of private corporations, etc.- - were always binary.

Acknowledgements Open Access funding provided by Projekt DEAL.

Open Access This article is licensed under a Creative Commons Attribution 4.0 International License, which permits use, sharing, adaptation, distribution and reproduction in any medium or format, as long as you give appropriate credit to the original author(s) and the source, provide a link to the Creative Commons licence, and indicate if changes were made. The images or other third party material in this article are included in the article's Creative Commons licence, unless indicated otherwise in a credit line to the material. If material is not included in the article's Creative Commons licence and your intended use is not permitted by statutory regulation or exceeds the permitted use, you will need to obtain permission directly from the copyright holder. To view a copy of this licence, visit http://creativecommons.org/licen ses/by/4.0/.

\section{References}

Aleskerov F, Kalyagin V, Pogorelskiy K (2008) Actual voting power of the IMF members based on their political-economic integration. Math Comput Modell 48(9-10):1554-1569

Alonso-Meijide JM, Bowles C (2005) Generating functions for coalitional power indices: an application to the IMF. Ann Oper Res 137(1):21-44

Barry B (1980) Is it better to be powerful or lucky? Part II. Polit Stud 28(3):338-352

\footnotetext{
${ }^{8}$ Confer www.imf.org/en/News/Articles/2019/10/19/communique-of-the-fortieth-meeting-of-the-imfc.
} 
Foreign Affairs (2011) Can the BRICS take the IMF? https://www.foreignaffairs.com/articles/201106-09/can-brics-take-imf. Accessed 24 July 2020

Kurz S (2016) Computing the power distribution in the IMF. arXiv:1603.01443v1

Laruelle A, Martínez R, Valenciano F (2006) Success versus decisiveness: conceptual discussion and case study. J Theor Polit 18(2):185-205

Laruelle A, Valenciano F (2005) Assessing success and decisiveness in voting situations. Soc Choice Welfare 24(1):171-197

Leech D (2002) Voting power in the governance of the International Monetary Fund. Ann Oper Res 109(1-4):375-397

Leech D (2003) Computing power indices for large voting games. Manag Sci 49(6):831-837

Leech D, Leech R (2013) A new analysis of a priori voting power in the IMF: recent quota reforms give little cause for celebration. In: Holler MJ, Nurmi H (eds) Power, voting, and voting power: 30 years after. Springer, Heidelberg, pp 389-410

Riker WH (1982) Liberalism against populism. Waveland Press, Long Grove

Publisher's Note Springer Nature remains neutral with regard to jurisdictional claims in published maps and institutional affiliations. 